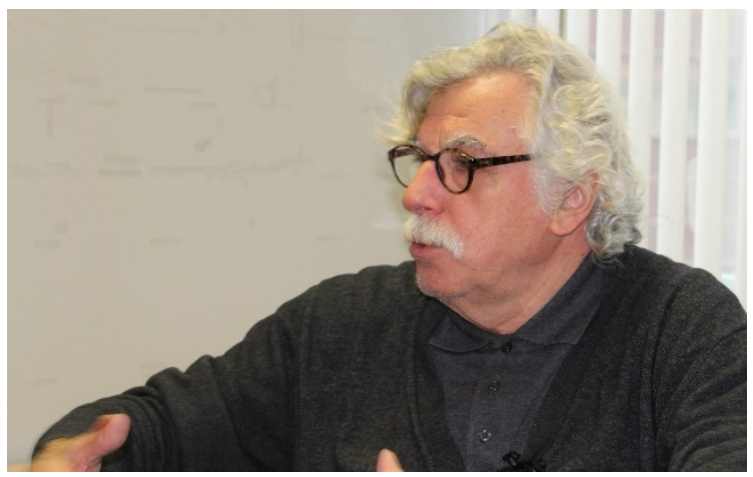

\title{
Jesús Contreras o els inicis autodidactes de I'antropologia catalana
}

\author{
Griselda Ballester, Elisabet Marcos, Andrea Milán, Isabel Lopez, Helena \\ Moreno, Jessica Morente, Paula Villanueva ${ }^{1}$ - Universitat Autònoma de
} Barcelona ${ }^{2}$

DOI: https://doi.org/10.5565/rev/periferia.635

\begin{abstract}
Resum
En aquesta ocasió el Projecte Entrevistes ha tingut el privilegi de conversar amb el professor Jesús Contreras just abans de que es jubilés de la Universitat de Barcelona. Fent un recorregut per la seva vida i recerques coneixem l'experiència inicial amb la disciplina d'un dels primers deixebles de Claudi Esteva, la seva recerca etnogràfica sobre curanderisme i padrinatge al Perú, així com el seu paper en la fundació de I'Institut Català d'Antropologia. La segona part de l'entrevista focalitza en I'especialització de Contreras en l'antropologia de l'alimentació i la creació de I'ODELA (Observatori De I'Alimentació). Fent gala de la seva gran memòria i capacitat conversadora, Contreras ens ofereix un relat d'alguns dels moments més importants dels desenvolupament contemporani de l'antropologia catalana, de la qual ha estat i segueix essent un dels seus més destacats promotors.
\end{abstract}

Paraules clau: Jesús Contreras, entrevista, antropologia catalana, antropologia de I'alimentació, història de I'antropologia

\section{Resumen}

1 Autora de les fotografies: Jessica Morente.

Directora: Montserrat Clua i Fainé

2 Enviar correspondència a: Montserrat.clua@uab.cat 
Ballester et al., Jesús Contreras o els inicis autodidactes de l'antropologia catalana, perifèria 23(1), junio 2018

\section{revistes.uab.cat/periferia}

En esta ocasión el Proyecto Entrevistas tuvo el privilegio de conversar con el profesor Jesús Contreras justo antes de que se jubilara de la Universitat de Barcelona. A través de un recorrido por su vida e investigaciones conocemos la experiencia inicial de la disciplina de uno de los primeros discípulos de Claudio Esteva, su investigación etnográfica sobre curanderismo y compadrazgo en Perú, así como su papel en la fundación del Instituto Catalán de Antropología. La segunda parte de la entrevista focaliza en la especialización de Contreras en la antropología de la alimentación y la creación del ODELA (Observatorio De la Alimentación). Haciendo gala de su gran memoria y capacidad conversadora, Contreras nos ofrece un relato de algunos de los momentos más importantes de los desarrollos contemporáneos de la antropología catalana, de la cual ha sido y sigue siendo uno de sus más destacados promotores.

Palabras clave: Jesús Contreras, entrevista, antropología catalana, antropología de la alimentación, historia de la antropología

Eli Marcos: Bon dia i, primer de tot, moltes gràcies per accedir a respondre a les nostres preguntes. Començarem l'entrevista fent una mica de repàs a la seva biografia. Segons les nostres fonts, quan tenia 18 anys va venir a Barcelona a estudiar filosofia. Des de la filosofia, com va trobar I'antropologia?

Jesús Contreras: Jo vaig arribar a la filosofia vocacionalment. En aquella època a la facultat de Filosofia i Lletres de la Universitat de Barcelona es feien dos anys comuns, i a partir de tercer hi havia una sèrie d'especialitats. La meva especialitat volguda, vocacional, era la de filosofia, però aquesta em va decebre força a partir del quart any, que va coincidir amb el meu servei militar. Jo vaig haver de fer la mili normal a causa de la Caputxinada i vaig fer el quart curs com vaig poder, perquè llavors no hi havia universitat a distància. Però en aquest curs ja quasi que m'interessava més per la psicologia, i fins i tot per la història, que per la filosofia estrictu sensu. Però bé, ja estava a quart i vaig decidir acabar fent cinquè. Un company meu, el Joan Frigolé que era d'un curs davant meu, quan jo estava a finals de quart un dia em diu: "Jesús, ha arribat aquí un antropòleg de Madrid que ens pot interessar". Jo ni sabia qui era I'antropòleg ni sabia què era l'antropologia. Però com que sóc una persona que no tinc iniciativa però sóc obedient, i el Joan Frigolé era molt amic meu i a més a més una persona molt respectable, doncs escolta, vaig anar amb ell a veure el Claudi Esteva i Fabregat, que era I'antropòleg que venia de Madrid (però s'havia format a 
Ballester et al., Jesús Contreras o els inicis autodidactes de l'antropologia catalana, perifèria 23(1), junio 2018

\section{revistes.uab.cat/periferia}

Mèxic). El Joan li va dir que estàvem interessats en l'antropologia i el Claudi Esteva ens va acollir molt bé. De fet ell acabava d'arribar i suposo que li va agradar que d'entrada ja trobés gent interessada, i no de primer any sinó un llicenciat i un a punt de llicenciar-se. Aleshores, és clar, no en teníem ni idea de res de l'antropologia i el Claudi Esteva per començar ens va recomanar cinc llibres d'antropologia que estaven en castellà. El llibre de Herskovits, El hombre y sus obras, és el primer que vaig llegir d'antropologia. Es va donar la casualitat que l'any que jo vaig fer cinquè, que va ser el curs 69-70, va coincidir amb el primer any del què es va dir en aquella època el Pla Maluquer. El Joan Maluquer de Motes era el degà de la Facultat, un catedràtic de prehistòria que va fer canvis a la universitat. Per primera vegada es podien fer assignatures optatives i aleshores jo em vaig poder matricular d'Antropologia Cultural, que de fet era una assignatura de primer o segon, però amb el nou pla ho podia fer. Anava a les classes a les 8 del matí, tots els dies. Allà, entre les classes de I'Esteva - que era molt detallista en les seves classes- i la lectura de El hombre y sus obras, l'Antropologia del Kluckhohn i d'altres llibres, vam començar a fer antropologia. Érem quatre persones, totes de Filosofia: el Joan Frigolé (que ja havia acabat), jo i després dos altres companys de curs meus, en Paco Macià i la Montserrat Camps, que també això de la filosofia ja els havia començat a decebre. Ens llegíem aquests llibres i ens els explicàvem a nosaltres mateixos, fèiem com una mena de seminari. Aquest va ser l'inici.

\section{E: I després, com van passar de l'antropologia teòrica a la pràctica?}

J.C.: Aquest mateix curs del 69-70, al desembre-gener, el Claudi Esteva estava portant una recerca a Bielsa, el Pirineu aragonès, i ens va dir que ens hi portava. Jo no sé ni si havia acabat de llegir el Herskovits que l'Esteva ens porta a fer el treball de camp a Bielsa. En ple hivern amb un fred que fotia tremendo, i vam estar allà deu dies. L'home ens deia: "Surtin, no vagin junts, cadascun pel seu costat". Però collons, sortíem al poble i no hi havia ningú! Ara si aneu a Bielsa a l'estiu està ple gent, com ha crescut allò... Però en aquell moment era un poble de tres-cents habitants; sortia i al cap de dos minuts em trobava al Paco Macià de seguida... la gent ens mirava... Diríem que em va marcar molt la frustració que va suposar això. De fet, quan jo vaig donar tècniques d'investigació, una de les coses que volia era evitar que la gent 
Ballester et al., Jesús Contreras o els inicis autodidactes de l'antropologia catalana, perifèria 23(1), junio 2018

\section{revistes.uab.cat/periferia}

tingués una frustració com la que jo vaig tenir. Aquest va ser el meu inici de treball de camp, no gaire... diríem... satisfactori.

El doctor Esteva també estava formant part de la "Misión Española en el Perú" del Ministerio de Asuntos Exteriores, que estaven excavant unes ruïnes a Chinchero, molt a prop del Cuzco. Ens va dir: "Em puc endur a un de vostès al Perú". El candidat òbviament era en Joan Frigolé, perquè ja era llicenciat i a més a més és el que en el treball de camp a Bielsa ho havia fet millor. Però el Joan Frigolé havia estat tres mesos a la Model, perquè havia estat delegat de curs a Filosofia en ple franquisme i va estar detingut. Aleshores no va poder tenir el certificat de penals ni, per tant, el passaport. Jo per sort, com ja havia fet la mili quan estava a quart, tenia passaport. Per tant, gràcies a un càstig resulta que jo estic aquí parlant amb vosaltres: hi havia d'anar en Frigolé, però com que en Frigolé no hi podia anar, aleshores el segon era jo. Total, que jo vaig anar al Perú sense tenir ni idea de res. Vaig anar allà d'ajudant del doctor Esteva i va ser el meu segon bateig. Però aquest no va ser frustrant, perquè sorties pel carrer i la gent t'abordava, no costava parlar amb ells. És a dir, que en molt poc temps vaig fer una lectura i una pràctica intensives i bé, em va agradar això de I'antropologia. Perquè he de reconèixer que en aquella època jo també tenia unes certes vel-leïtats esotèriques, eh. De fet el meu treball de Ilicenciatura va ser Empirismo y superstición en la medicina popular y en la medicina científica del siglo XVIII. Això de la superstició m'interessava molt. Però bé, jo anava com ajudant i de fet aplicava els qüestionaris que havia preparat el doctor Esteva.

Aquests van ser els meus inicis, una casualitat darrera l'altra. Sóc obedient: el Joan Frigolé suggereix i jo vaig amb ell. Llegeixo el Herskovits i m'agrada. Anem a Bielsa, amb certa frustració això sí, perquè a més jo sóc una persona força extravertida i pensava que ser extravertit de cara al treball de camp seria positiu. Doncs a Bielsa em va sortir tota la meva timidesa! I finalment lo de Chinchero que sí que va ser força agradable per mi. Doncs, aquest és el meu inici.

\section{E: Llavors aquest primer grup que estaves comentant és el primer grup que començarà a donar classes d'antropologia a Barcelona?}


Ballester et al., Jesús Contreras o els inicis autodidactes de l'antropologia catalana, perifèria 23(1), junio 2018

\section{revistes.uab.cat/periferia}

J.C.: El doctor Esteva donava una Antropologia Cultural, que era de primer o segon curs, una Introducció a la Sociologia, a la qual també em vaig matricular, i després donava una Etnologia dels Pobles Primitius, que aquesta la vaig seguir ja Ilicenciat. Anava a classe perquè era el doctor Esteva i perquè nosaltres teníem un dèficit de formació extraordinari. Llavors d'aquest primer grup, el Joan Frigolé i jo vam seguir, el Paco Macià va treure unes oposicions d'institut i la Montse Camps es va dedicar al macramé, tal qual. L'any següent es va incorporar el Joan Prat i després d'altres persones, però aquest va ser el nucli inicial. Després també hi havia el Pau Comes que va fer un treball de camp a Argelaguer, per la Garrotxa amb I'Esteva, que també tenia coses per allà. Es va dedicar a la història, es va treure les oposicions d'institut i va seguir un temps amb nosaltres però al final l'institut se'l va quedar. Després també molt aviat es va incorporar I'Ignasi Terradas que va ser un dinamitzador del seminari autodidacta que nosaltres teníem. L'Ignasi Terradas tenia una enorme capacitat de lectura i és una persona súper intel-ligent; per mi és com el nostre premi Nobel, per dir-ho d'alguna manera. A més cal tenir en compte una altra cosa: ni el Joan Frigolé ni jo, cap de nosaltres, havia estudiat anglès. Nosaltres érem de fer francès al batxillerat, o sigui que vam haver de fer tots cursos intensius d'anglès perquè la bibliografia estava en anglès. Doncs I'Ignasi ja llegia anglès i ens feia, amb paper d'aquest d'envelar, uns quadros resum que escolta, llàstima no haver fet fotos dels esquemes que preparava I'Ignasi! Diríem que aquest autodidactisme va ser un complement de la formació que no vam tenir cap de nosaltres: ni en Joan Prat, ni en Joan Frigolé, ni jo. L'Ignasi Terradas va anar a fer un màster a Manchester una mica més endavant, però cap de nosaltres va tenir formació en antropologia. Aleshores, érem uns autodidactes amb tots els dèficits i els desavantatges que això suposa. Però, vist en perspectiva, també va tenir, des del meu punt de vista, un cert avantatge, que és que érem d'una receptivitat extraordinària. O sigui, el nostre complex de no formació en antropologia era tan gran que qualsevol cosa que arribava ens la llegíem. Érem, en un primer moment, gens crítics: tot el que era d'antropologia era ben rebut. Aquell va ser el procés de formació inicial que vam tenir aquest grup. Després es va anar incorporant més gent, en Joan Bestard i molta altra gent. 
Ballester et al., Jesús Contreras o els inicis autodidactes de l'antropologia catalana, perifèria 23(1), junio 2018

\section{revistes.uab.cat/periferia}

\section{E.: Perquè clar, quan vostès estaven fent això no hi havia encara la formació com a tal en antropologia i per tant, ho havien de fer així.}

J.C.: No, no, aquesta és la segona part. Teníem aquestes assignatures que el doctor Esteve donava, Etnologia dels pobles primitius i Introducció a l'antropologia cultural, que eren cursos molt generals. Resulta que amb el Pla Maluquer i la divisió de la Facultat, de cop i volta un any es posa l'Antropologia cultural com una assignatura obligatòria de primer per a totes les carreres de la Facultat: hi havia un primer any comú. Aleshores de cop hi ha onze grups d'antropologia cultural que aquesta petita tribu que érem aquest grup inicial vam haver de començar a donar. No teníem ni idea d'antropologia i resulta que havíem de donar-ne classes. Hi ha aquell acudit que diu: "¿Usted sabe inglés?" "No, pero para enseñar...". Doncs escolta: "¿Usted sabe antropología?" "No, pero para enseñar..." (riu). Tots vam començar a donar aquesta antropologia cultural a un parell de grups i ho anàvem preparant sobre la marxa: ens intercanviàvem les fitxes perquè s'havia de rendibilitzar l'esforç! (riem tots). A veure, jo ho dic una mica en broma però no és tant de broma, eh, perquè va ser així. 0 sigui, havies de donar un curs d'antropologia cultural quan de fet no tenies formació. Sort que en aquella època nosaltres érem "penenes" (PNN, Professors No Numeraris, és a dir, no funcionaris) i fèiem vaga cada dos per tres. Entre les vagues dels estudiants i les vagues dels "penenes", hi havia molts pocs dies de classe, afortunadament, i ens ho podíem preparar una mica. Amb tot i això anàvem amb I'aigua al coll. A més hi havia una cosa positiva que hem de dir: nosaltres teníem amor a l'antropologia i amor propi. Això de fer el ridícul no agrada a ningú, en principi. Aleshores era com anar-ho preparant sobre la marxa. Ja us dic, nosaltres no vam fer cap carrera. L'especialitat d'antropologia va començar força més tard. 
Ballester et al., Jesús Contreras o els inicis autodidactes de l'antropologia catalana, perifèria 23(1), junio 2018

\section{revistes.uab.cat/periferia}

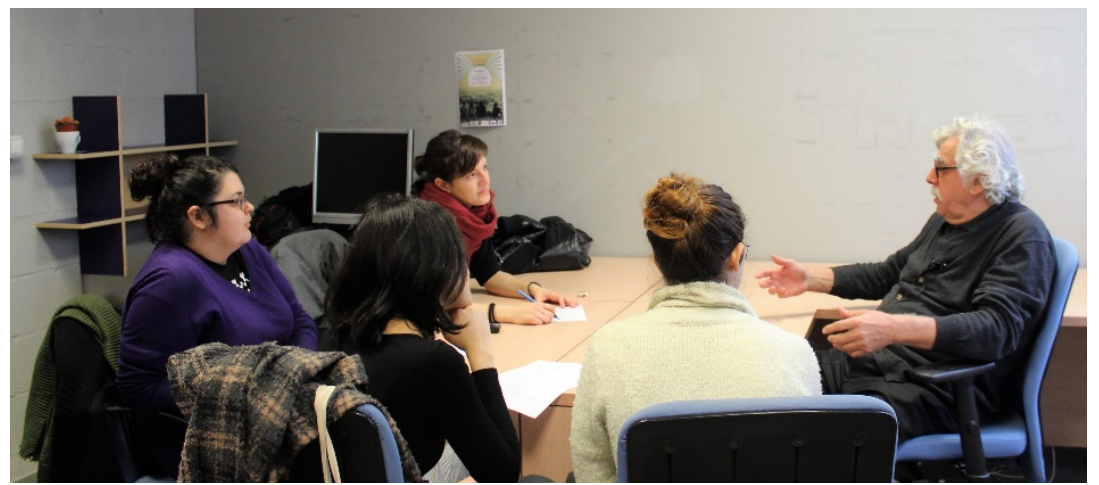

Helena Moreno, Andrea Milán, Elisabet Marcos, Paula Villanueva i Jesús Contreras

\section{E.:Tenint en compte tot això, quines influències o referents va tenir?}

J.C.: El doctor Esteva ens va recomanar una pila de llibres que tots eren del Fondo de Cultura Econòmica. De fet era I'editorial que més havia traduït coses d'antropologia al castellà, ja que és una editorial mexicana i a Mèxic l'antropologia ha estat sempre molt desenvolupada. Aquí d'editorials pràcticament no hi havia res, alguna cosa de Paidós, que era una editorial argentina, i poc més. Ja t'he dit que nosaltres érem autodidactes i molt receptius, ho llegíem tot i no fèiem distincions entre, què diré jo, la Cultura i Personalitat - que és l'escola dins la qual el Claudi Esteva s'hagués apuntat- i una altra perspectiva. L'Abram Kardiner té un llibre que és El individuo y su sociedad que vaig llegir i que a mi em va marcar molt en aquell moment. Una primera influència que ningú ho diria, perquè després jo he estat I'antítesi d'aquest tipus d'escola, no? Però, ja ho he dit abans, en aquell moment nosaltres llegíem essent completament acrítics; després amb el temps, sí que vam ser més crítics. Us posaré per exemple la meva tesi. La meva tesi (perquè veieu la relació amb l'esoterisme al qual em referia abans) es titula Adivinación, ansiedad y cambio social en Chinchero, los Andes sur del Perú. L'ansietat venia de Kardiner, de I'escola de Cultura i Personalitat i tot aquest tipus de coses. Quan vaig publicar part de la tesi el Ilibre es titula Subsistencia, ritual y poder en los Andes; o sigui, I'ansietat es converteix en subsistència. Per què aquest canvi en el títol? 
Ballester et al., Jesús Contreras o els inicis autodidactes de l'antropologia catalana, perifèria 23(1), junio 2018

\section{revistes.uab.cat/periferia}

Jo vaig quedar impressionat, quan era a Chinchero, amb els endevins que hi havia, que es diuen pacos. Són com curanderos que amb les fulles de coca feien el cocacawai, la adivinación por la coca (cocacawai significa "mirar la coca"). Aleshores, la gent que vol fer una consulta a l'endeví o al paco va allà amb un saquet (és a dir amb un mocador amb coca i amb una moneda d'un sol de plata) i l'endeví, el paco, ho agafa, ho tira i llegeix la coca. Jo ho vaig veure i em vaig quedar parat. Vaig preguntar: "Escolti, la gent què consulta?" Bé, la gent anava a consultar a l'endeví perquè li mirés la coca sobre malalties de les persones, malalties del bestiar i robatoris, fonamentalment. Però jo pensava si hi havia consultes de amor i aquest tipus de coses. Em vaig interessar per l'endevinació i a partir d'aquí va sortir la tesi. Aleshores, per què l'ansietat? Perquè la gent les consultes les feien de les coses que els preocupaven: els robatoris, les malalties del bestiar, etc. Així doncs, l'escola de Cultura i Personalitat va ser una influència difusa. Però es clar, nosaltres érem (de l'època d'estudiants i després), gent d'esquerres, per dir-ho d'alguna manera. I aleshores havies de ser marxista i el marxisme era Marx. Però jo en un determinat moment, relativament aviat, descobreixo el Maurice Godelier, "el antropólogo marxista"! Ostres, tu, s'ajunten les dues coses, fantàstic! Però l'antropologia marxista dels francesos dels anys 70 no té res a veure, són les antípodes pràcticament, de la Cultura i Personalitat! A mi la tesi m'agafa en aquesta etapa de canvis. No l'he tornat a llegir la meva tesi, eh! (riu) Aleshores jo he anat cap a una antropologia diriem més marxista, més interessat pel tema del treball, la subsistència, l'organització social i política, etc. També tenia un avantatge Godelier, i és que publicava en francès i jo el francès el dominava a l'època. Vaig llegir Godelier, Pierre Philipe Rey, Claude Meillasoux... A més hi ha una altra qüestió i és que jo donava antropologia econòmica. Ells em van influenciar considerablement.

Normalment a l'antropologia la gent ha fet el canvi, alguns que comencen sent materialistes o marxistes s'han passat a la postmodernitat. Doncs jo no; jo vaig començar com a postmodern quan encara no hi havia antropologia postmoderna i he acabat amb l'antropologia materialista més grollera, per dir-ho d'alguna manera. També en els anys 70, es van començar a publicar amb castellà monografies, fonamentalment d'antropòlegs americans (malgrat que l'iniciador va ser el Pitt-Rivers 
Ballester et al., Jesús Contreras o els inicis autodidactes de l'antropologia catalana, perifèria 23(1), junio 2018

\section{revistes.uab.cat/periferia}

amb el The People of the Sierra, que es va traduir relativament aviat al castellà). I després hi havia molts antropòlegs deixebles de I'Eric Wolf, que també és un dels autors que a mi em va influenciar força en relació a la pagesia, al camperolat. Aquesta va ser una de les nostres, diríem, derivacions o especialitzacions. Una altra influència que també em va impactar quan el vaig llegir, quan jo estava amb el meu esoterisme, va ser Las brujas y su mundo de Julio Caro Baroja. Vaig escriure a Caro Baroja i em va contestar! Això en aquell moment ja em va meravellar, perquè jo era una criatura de vint-i-tres anys. Ho dic retrospectivament, perquè Caro Baroja era tot un personatge. Et contestava cartes però en canvi tu l'invitaves a una conferència i no venia; et deia que sí i després no es presentava! Doncs bé, Las brujas y su mundo també em va influenciar molt.

\section{E.: Llavors, pel que fa a la seva etapa ja de professor, com va entrar a la UB, ja ha dit que era una mica de casualitat...}

J.C.: A veure, després d'anar al Perú, vaig acabar la carrera i vaig entrar de professor a un institut. Donava classes de llengua, que em van anar molt bé perquè vaig aprendre a escriure, a fer resums... Donant classes s'aprèn molt (riu). Me'n recordo que un dia estàvem aquí, al claustre de l'edifici antic de la universitat (a plaça Universitat) i el doctor Esteva em va dir: "Escolti, Jesús, vol ser ajudant vostè?". Li vaig contestar: "Sí, sí, i tant", "Doncs vingui a signar!" En aquella època les coses funcionaven així. Vaig signar un contracte d'ajudant que era compatible amb ser professor d'institut (que ara no ho seria, eh!) i vaig estar cinc anys en un institut, donant classes de llengua i d'ajudant a la UB. En aquella època un ajudant de ciències, per exemple química, es feia un fart de fer pràctiques al laboratori però nosaltres no fèiem gairebé res. La nostra tasca era donar-li al doctor Esteva una classe de tant en tant, vigilar exàmens, corregir exàmens... Me'n recordo d'una vegada...! (riu) Em vaig passar tota la nit sense dormir preparant la classe de I'endemà. Arribo a la classe i dic: "Avui el doctor Esteva no vindrà i faig la classe jo". Escolta tu, només dir això i la meitat de la classe ja s'aixeca i l'altra meitat quasi es va anar aixecant a mesura que avançava! (riu) 
Ballester et al., Jesús Contreras o els inicis autodidactes de l'antropologia catalana, perifèria 23(1), junio 2018

\section{revistes.uab.cat/periferia}

Vam començar d'ajudants i mentrestant fèiem les nostres tesis: en Joan Frigolé a Múrcia i jo anava als Andes als estius. Vaig anar-hi tres o quatre estius seguits. I després van començar les classes aquestes que us deia abans, que hi havia varis grups d'Introducció a l'antropologia cultural. I deuria ser als anys 75, 76077 (ara no ho recordo exactament), quan van començar a oferir més matèries: havíem de donar Etnologia de la Península Ibèrica, Antropologia econòmica, Història de I'antropologia, Cultura i personalitat, Antropologia del parentiu, Etnologia dels pobles primitius,... Bé, vàries assignatures a part de les d'introducció. Ens ho vam repartir: a mi em va tocar Antropologia econòmica i l'Etnologia de la Península Ibèrica. L'antropologia econòmica me la vaig inventar, molt manualment. Jo sempre he estat molt artesà: de tots els llibres que tenia d'antropologia econòmica em vaig fer una fitxa dels índexs i a partir d'aquí em vaig constituir un programa. I l'Etnologia de la Península Ibèrica la vam construir amb en Joan Prat. L'heu entrevistat el Joan Prat, no? Suposo que ell també us haurà explicat el que us explico jo: amb el Joan Prat vam fer un viatge iniciàtic. Havíem de donar I'Etnologia de la Península Ibèrica i no en teníem ni idea. A més a més el concepte "Península Ibèrica" ja era una cosa heretada: no era Etnologia d'Espanya sinó de la Península Ibèrica, i no hi havia pràcticament bibliografia, tot just es començava a publicar alguna monografia. Aleshores amb el Joan Prat vam fer un viatge per Espanya, a fer una mena de reconeixement i contactar amb tota una sèrie d'adreces de gent que estava donant etnologia: gent del País Basc, Andalusia, Portugal... Perquè clar, Península Ibèrica incloïa Portugal, eh!, i teòricament no incloïa ni Canàries ni Ses Illes. Al final quan vam fer el programa vam excloure Portugal i no vam excloure les illes. El viatge va ser molt divertit perquè anàvem a la caça de l'informant: estàvem desitjant que algú fes autoestop per pujar-lo i entrevistar-lo. Al País Basc vam anar a veure el Caro Baroja! Ens va rebre a casa seva, ens va regalar quasi tots els llibres que ell tenia, va ser molt amable amb nosaltres. També vam entrevistar algunes persones a Portugal, alguns a Andalusia (ja portàvem tres setmanes, un acalorament...), i vam passar per Múrcia perquè el Joan Frigolé hi estava fent el treball de camp.

Així doncs, vam construir un programa en funció de la bibliografia que hi havia i de la nostra concepció, que ja començàvem a tenir en aquelles èpoques i que aleshores 
Ballester et al., Jesús Contreras o els inicis autodidactes de l'antropologia catalana, perifèria 23(1), junio 2018

\section{revistes.uab.cat/periferia}

sí que ja era una mica crítica, per no dir força crítica, amb la majoria de monografies dels antropòlegs americans que havien vingut aquí a Espanya. Una de les coses que més ens va sobtar i amb què vam ser més crítics va ser el sincronisme o presentisme de totes aquelles monografies. O sigui, arribava una persona i no preguntava pels antecedents. Nosaltres trobàvem que els antecedents o la història eren fonamentals per comprendre qualsevol institució o el propi canvi social. No pots parlar de tradició i modernitat, que eren molt habituals en aquell moment, com si res. Com si la modernitat hagués començat "en aquest poble l'1 de setembre de 1972", per dir alguna tonteria. Doncs aquestes crítiques les vam començar a fer llavors amb en Joan Prat. Ens repartíem les lectures i fèiem fitxes dels llibres i ens les intercanviàvem. Ell donava I'assignatura a Tarragona i jo a Barcelona.

\section{E.: Dins la mateixa època, a finals de la dècada dels setanta, una sèrie d'antropòlegs vau decidir que s'havia de fer l'Institut Català d'Antropologia. Qui va fundar l'Institut?}

J.C. En sembla que a l'acte de fundació vam ser 16 o 17 signatures: en Joan Frigolé, Joan Prat, Dolors Comas, Juanjo Pujades, Oriol Romaní, Dolors Llopart... I ara som més de 300 !

\section{E.: Per què va sorgir l'ICA i com va ser l'experiència?}

J.C.: La iniciativa de crear un institut d'antropologia va ser perquè nosaltres vam ser molt poc crítics durant una sèrie d'anys, però a partir d'un determinat moment el nostre aparell crític sí que es va desenvolupar una mica. I ens vam adonar que la universitat en aquell moment era una mena de cul de sac. Nosaltres continuàvem tenint el complex d'inferioritat de l'autodidactisme i ens adonàvem que ens havíem d'obrir a gent molt diversa. Hi havia el Josep Ramon Llobera que estava a Londres però venia molt sovint per aquí i òbviament ens vam apropar de seguida a ell. Era una persona extraordinàriament receptiva i generosa, i que tenia molts contactes. Una de les primeres raons per què vam crear I'Institut va ser per poder convidar gent que vingués a fer seminaris aquí, fora de la universitat. Perquè a la universitat, sense entrar en detalls, no els podíem fer. Els seminaris els vam poder fer gràcies als contactes d'en Llobera, que jo sempre he dit que va ser el nostre Ministre 
Ballester et al., Jesús Contreras o els inicis autodidactes de l'antropologia catalana, perifèria 23(1), junio 2018

\section{revistes.uab.cat/periferia}

d'Assumptes Exteriors. El primer seminari que vam fer va ser amb en Jonathan Friedman, que era molt jove però ja era una figura en aquells moments. Va venir aquí perquè nosaltres li vam pagar el viatge (cobràvem una inscripció pel seminari). Pels seminaris de I'ICA van passar persones molt i molt il.lustres de l'antropologia europea i nord-americana. Alguns noms que ara diran poca cosa però que llavors eren primeres figures d'Anglaterra, França, Mèxic...etcètera. Com Lawrence Krader, Ángel Palerm (que també ens va donar molts contactes), Godelier, Pierre Bonte, Olivia Harris... En fi, quantitat de gent. Era una manera d'obrir-se, d'obrir els camps. Fèiem tres o quatre seminaris només pagant-los el viatge i l'allotjament i van venir encantats.

Després òbviament l'institut es va fer més gran, hi havia un interès de difondre I'antropologia aprofitant els contactes, el que ara en diem xarxes socials. Per exemple, vam organitzar un cicle de conferències que va pagar la Caixa perquè un dels que hi treballava era cunyat del Joan Prat. Portàvem els recursos a tots nivells, amb el que hi havia llavors. La raó per la que es va crear I'ICA, doncs, va ser per intentar compensar una miqueta el que oferia la universitat, obrir i diversificar la nostra formació, enriquir-la.

Jessica Morente: Dit així, sembla que aquesta mena de complex d'inferioritat també va ser positiu, per les ganes d'aprendre.

J.C.: Sí, d'alguna manera, vist en perspectiva, el nostre complex d'inferioritat va tenir alguns avantatges. Si nosaltres haguéssim quedat absolutament satisfets de la nostra des-formació o no-formació hauria estat una altra història.

\section{E.: Això de que portéssiu gent d'altres llocs té alguna relació amb que vingués en John Murra i acabés fent una donació de la seva biblioteca?}

J.C.: En Murra jo I'havia llegit perquè jo era andinista. Ens el va contactar I'Angel Palerm, que eren molt amics. En Murra va venir encantadíssim, a més ell havia estat brigadista. Va venir vàries vegades, també a la Universitat de Barcelona, on és Honoris Causa. Era un personatge. Tenia una biblioteca generalista, amb moltes coses d'etnohistòria i la seva part andinista. I la vam comprar a I'ICA. Ho vam disfressar de donació perquè era més elegant però va costar 5 milions de pessetes. 
Ballester et al., Jesús Contreras o els inicis autodidactes de l'antropologia catalana, perifèria 23(1), junio 2018

\section{revistes.uab.cat/periferia}

Teníem un molt bon contacte a la diputació de Barcelona que llavors estudiava antropologia i que ens va aconseguir que la diputació posés els diners per comprar la biblioteca de Murra, que havia d'anar a la Biblioteca de Catalunya. Però quan van arribar un parell de contenidors plens de llibres la Biblioteca de Catalunya va dir que no tenien Iloc ni recursos per catalogar-ho, de manera que es va quedar a I'ICA. Vam organitzar els que als Andes en diuen una mita, un treball d'ajut cooperatiu: vam convocar uns quants socis de I'ICA i 10 o 12 persones vam portar els contenidors de llibres al local de I'ICA, que llavors estava al carrer Urgell i els vam descarregar. Ara aquesta biblioteca està cedida a la UAB. Això també era una dels dèficits que teníem, un dèficit bibliòfil.

\section{E.: I què va aportar l'ICA a l'antropologia catalana?}

J.C.: Bé, això és una pregunta que no $\mathrm{m}$ 'he fet mai. Algunes coses ha aportat en els seus quasi 40 anys d'història. Són molts anys. Algú hauria de fer en un treball de fi de grau o de màster una història de I'ICA, una mica les seves diferents fases. La primera fase és aquesta en la que jo organitzava aquests seminaris i com que els recursos eren escassos, molts s'allotjaven a casa meva. Érem militants de I'antropologia i això és una evidència de les nostres precarietats per una banda, però de la nostra convicció antropològica per una altra. Doncs en un primer moment I'ICA va ajudar també a obrir-nos a l'exterior. La poca o molta antropologia que es feia aquí en aquells moments també va ser coneguda, perquè la gent que va venir aquí ho va fer de bon grat i es van mantenir les relacions. Per tant, una primera aportació va ser el que diríem una "primera internacionalització" de l'antropologia catalana dins del que eren les condicions de l'època. No només venia gent aquí, sinó que els contactes internacionals també van facilitar que nosaltres anéssim a fora. L'Ignasi Terradas va fer el màster, jo vaig estar invitat pel Godelier tres mesos, o la Dolors Comas i molta altra gent.

Un altre punt va ser una certa sensació o comportament de col·lectivitat professional. Penseu que I'antropologia d'aquells moments era absolutament desconeguda. Quan s'estava discutint la televisió catalana (és a dir, a finals dels setanta, amb els inicis de I'autonomia), Jordi Pujol, President de la Generalitat, va dir "No volem una 
Ballester et al., Jesús Contreras o els inicis autodidactes de l'antropologia catalana, perifèria 23(1), junio 2018

\section{revistes.uab.cat/periferia}

televisió antropològica", referint-se al que havia de ser TV3. Què vol dir això? Que no volia una televisió folklòrica en el sentit més negatiu del terme, com a sentit de pandereta o sardana. Això és un indicador del grau de coneixement que hi havia sobre I'antropologia en aquells moments. Doncs I'Institut també va crear una certa convicció de que la disciplina era pertinent, que tenia coses que podia aportar. Va crear un sentit, no de gremi però si de professió, de disciplina, i un intent de projectar-la a la societat catalana. Jo diria que aquestes dues coses van ser inicialment i fonamentalment el què va aportar l'ICA.

\section{E.: I tenint en compte que l'ICA aparegué relativament d'hora dins del què és l'antropologia en l'estat espanyol, quina rellevància diria que té dins del marc espanyol?}

J.C.: L'ICA, com bé dius, va ser el primer institut d'antropologia a Espanya. Després va aparèixer l'andalús, el madrileny, etc., quan ells potser no havien tingut els problemes o les raons que vam tenir nosaltres per crear I'ICA. Després es va crear la Federación de Asociaciones de Antropología del Estado Español, la FAAEE.

\section{Montse Clua: A la fundació de la FAAEE també hi vas estar?}

J.C.: Sí. En aquell moment hi havia I'Institut d'Antropologia de Barcelona, que portava Àngel Aguirre Baztán que era professor de psicologia i que va ser com una rèplica de I'ICA. Aleshores, quan es va crear la FAAEE no podia haver-hi més d'un institut per àrea regional o comunitat autònoma en la Federació i vam entrar I'ICA. Després això es va modificar, precisament en primera instància pels de Tarragona, perquè I'ITA (Institut Tarragonès d'Antropologia) també pogués ser membre de la FAAEE. Que per cert ara s'ha canviat el nom, no?

Montse: Sí, ara és la nova ASAEE.

J.C.: Bé, doncs diríem que aquests altres instituts es crearen veient un model, però cap d'aquests altres instituts organitzava els seminaris que nosaltres vam fer. També partien d'una altra base. A veure, I'Institut, en les seves declaracions fundacionals, vam dir que també tenia per objectiu obrir-se a la societat, hi havia un compromís. 
Ballester et al., Jesús Contreras o els inicis autodidactes de l'antropologia catalana, perifèria 23(1), junio 2018

\section{revistes.uab.cat/periferia}

Que bé, les declaracions fundacionals sempre són més ambicioses del que després es pot fer, però sí que hi havia un intent de vincular-se amb la societat.

Una altra de les coses que recordo és que en aquells moment hi havia el model de les tradicions populars. Hi havia el Museu Etnològic, el Museu d'Arts i Tradicions Populars, i allà hi treballava una sèrie de gent que després van entrar al ICA. De fet el primer president va ser en Joan Frigolé i la segona va ser la Dolors Llopart, que era conservadora del Museu d'Arts i Tradicions Populars. Nosaltres també volíem vincular una miqueta tota aquesta tradició d'estudi i afegir la part etnològica, folklòrica, en el bon sentit del terme. Hi va haver un intent de vincular tota una sèrie de gent que teníem un interès compartit i aquesta gent que treballava en aquests museus representava també la nostra voluntat de compromís amb la societat. $\mathrm{O}$ sigui, volíem que I'ICA fos una mena de succedani del que es podia fer a la societat i que no fos un col-lectiu d'universitaris frustrats. I en bona part jo penso que alguna d'aquestes coses sí que es van aconseguir. Volíem fer una pinya i va ser un espai de vinculació.

\section{E.: Com veu la continuació de l'antropologia catalana més enllà de I'ICA?}

J.C.: L'antropologia catalana es va diversificar considerablement. A part de l'Esteva a la UB (Universitat de Barcelona) va arribar el Ramón Valdés a la UAB (Universitat Autònoma de Barcelona), l'arribada del qual nosaltres no en vam tenir coneixement. Aquesta és una altra història. Vam conèixer el Ramón Valdés després de que en Joan Frigolé estigués un any a Madrid treballant pel Servicio de Extensión Agraria del Ministerio de Agricultura. Allà va tenir relació amb el Lisón, que gairebé no tenia contacte amb el Dr. Esteva. Era una època conflictiva. En aquell moment hi havia tres grans patums: el Caro Baroja (que era un cas apart), el Lisón i l'Esteva; i entre ells no hi havia gairebé cap relació. Madrid anava per una banda, amb el Carmelo Lisón, i després hi havia el departament de Antropología Americana, que aquests sí que tenien relació amb el Dr. Esteva. En fi, que el Lisón recomana al Joan Frigolé que visiti al Valdés i el Joan Frigolé acaba marxant a l'Autònoma. Ja dic, entre el Valdés i I’Esteva no hi va haver cap relació. 
Ballester et al., Jesús Contreras o els inicis autodidactes de l'antropologia catalana, perifèria 23(1), junio 2018

\section{revistes.uab.cat/periferia}

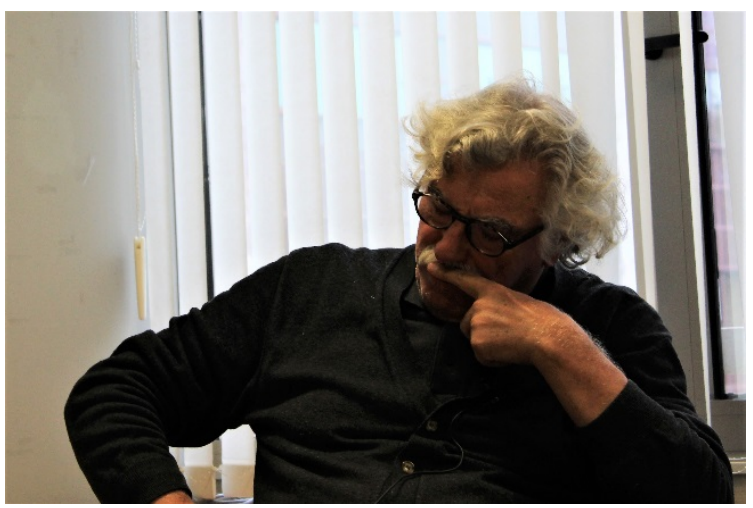

En tot cas, l'important és que l'antropologia es va anar diversificant. Després hi haurà Girona, que en un principi era una delegació de la Autònoma, i per una altra banda, Lleida i Tarragona, que eren delegacions de la UB, però després es converteixen en departaments propis. Aleshores, a Tarragona es fa un nucli important d'antropologia, amb en Joan Prat, en Josep Maria Comellas, I'Oriol Romaní, la Dolors Comas, en Juanjo Pujadas, etcètera. Òbviament, van augmentar el número d'assignatures d'antropologia que calia donar. Podria explicar tantes anècdotes... La primera vegada que es va donar classe d'antropologia en el que era la delegació de Lleida, la persona que la va donar era l'única persona que havia fet la tesina, i no havia fet antropologia. O sigui, en aquells moments tu acabaves i ja eres professor associat. Una cosa d'arribar i moldre però, es clar, amb uns dèficits...

També hem de tenir en compte la situació d'aquell moment, el context a l'estat espanyol del final del franquisme. L'inici de les autonomies provoca en molts dels antropòlegs i antropòlogues catalanes un canvi d'orientació important, també en algun antropòleg estranger. La qüestió de la identitat, el nacionalisme... La majoria de les monografies que trèiem aquí eren monografies d'un poble o monografies d'una comunitat. Bé, no dic que això sigui una aportació de l'antropologia catalana, però diríem que I'antropologia catalana o l'antropologia espanyola va fer això que se'n diu "fer de la necessitat virtut": al no tenir diners per fer treball camp a l'Amazones, a Nova Zelanda o on sigui, la gent estudiava al seu poble. O sigui I'anthropology at home la van inventar sense saber-ho els antropòlegs catalans o espanyols. Jo vaig 
Ballester et al., Jesús Contreras o els inicis autodidactes de l'antropologia catalana, perifèria 23(1), junio 2018

\section{revistes.uab.cat/periferia}

ser l'únic durant molt de temps que tenia treball de camp no at home, per dir-ho d'alguna manera.

Bé, la cosa es va diversificar en termes d'interessos i temàtiques per una qüestió demogràfica o quantitativa. També coincideix amb que es comença a criticar una mica els estudis de comunitat que es feien, aquestes monografies per calaixos: el que era parentiu, allò social, allò polític, religiós... I es passa a una antropologia que "problematitza" o que parteix d'una certa problematització. Aleshores les tesis deixen de ser estudis de comunitat. En aquella època moltes tesis tenien com a títol el nom o el pseudònim del nom del poble (ara si s'estudia un poble doncs es diu el nom del poble). En definitiva, en ampliar-se es diversifica.

\section{E.: I des del seu punt de vista, com ha estat el desenvolupament de I'antropologia espanyola?}

J.C.: Doncs mira, això també serviria per fer un treball de fi de grau o de màster. Una tesis doctoral no sé si dóna per tant, però... No es una feina fàcil. Tu agafes des del primer congrés fins al darrer, el dotzè o tretzè, que hi ha hagut a Espanya i t'entretens - ni que fos només amb els títols de les comunicacions que s'han presentat -, a mirar el què s'ha fet. Jo penso que d'entrada, un primer treball que quantifiqués o classifiqués tot el que s'ha presentat ja podria donar una certa idea, o si més no, plantejar-se un fotimer de preguntes per veure com ha evolucionat I'antropologia espanyola. Quan parlem de I'evolució de I'antropologia espanyola, parlem temàticament, metodològicament, teòricament, institucionalment... perquè es clar, tu pots analitzar aquesta evolució des de molts diferents punts de vista. L'evolució de I'antropologia espanyola va ser a les universitats, amb algunes assignatures; després va haver-hi especialitats o llicenciatures, graus i màsters; finalment graus a dues o tres universitats... etcètera. Aquesta és una evolució que vol dir que cada cop hi ha més antropòlegs especialitzats a la universitat o acadèmicament.

Després els museus també han evolucionat, o s'han creat ecomuseus que en bona mesura els manega gent relacionada amb l'antropologia. També hi hagué la creació de les autonomies, que va ser un moment important i que van contribuir a un cert reconeixement i estima de I'antropologia a llocs diversos. És a dir, hi ha diferents 
Ballester et al., Jesús Contreras o els inicis autodidactes de l'antropologia catalana, perifèria 23(1), junio 2018

\section{revistes.uab.cat/periferia}

indicadors per poder descriure i analitzar com ha evolucionat l'antropologia a Espanya, i a més a més, eventualment, avaluar-la. Però jo crec que algú s'hauria d'entretenir a fer-ho. Bé algú que en tingui moltes ganes, perquè ha de ser una tasca força avorrida; o sigui, jo suggeriria això com una tesi, però jo no la faria eh! (riu) Ara, sempre hi ha "gente pa' to"' que diuen. Doncs hauríem de trobar algú a qui li pogués motivar mínimament...

Una altra cosa seria, per exemple, analitzar l'evolució dels congressos. Hi va haver un moment que en dos, tres o quatre congressos (que jo ja estava fins el monyo), el nom dels simposis era sempre el mateix. Ara s'ha diversificat: els temes dels simposis no són tan "disciplinaris" o "subdisciplinaris" (tipus "antropologia del parentiu"), sinó temàtics o problemàtics; dibuixen camps, diríem, de problemes o de temes. Bé, això ho dic així "a brote pronto" com una primera constatació, però clar, seria un material a analitzar. Òbviament també es podria analitzar els temaris de les assignatures: com ha evolucionat una mateixa assignatura, sigui parentiu, religió, historia o econòmica. O les noves assignatures que han aparegut, com per exemple I'antropologia de l'alimentació, que ara es fa a un fotimer de llocs. Jo diria que aquí hi ha un reflex dels canvis o l'evolució de I'antropologia a nivell mundial, internacional, i eventualment de l'espanyola en particular. Però ja us dic que això es una tasca evidentment que algú s'hi hauria d'entretenir... Jo puc intuir coses, o puc dir quins elements poden servir per avaluar-ho, però no m'atreviria a dir com ha evolucionat això.

Per exemple, quan es va començar el grau d'antropologia (que d'això fa cinc o sis anys) hi va haver un canvi respecte al passat, on I'antropologia sempre havia estat una Ilicenciatura de segon cicle; és a dir, la gent que arribava a antropologia havia fet una altra cosa més abans. I de cop i volta, amb el pas a Grau, es comença a fer antropologia a primer de carrera. Però clar, la gent que arribava d'un institut, què carai pensaven o sabien d'antropologia? Jo em deia, "estem fent un grau nou i igual no ve ningú, no? I si ve algú que es pensa que fem antropologia forense?" Perquè clar, hi ha algunes sèries a la televisió en les que la disciplina d'antropologia apareix molt, però és una antropologia forense que nosaltres no fem. I jo m'imaginava que aquí vindria gent perquè pensaven que I'antropologia era això... No, no es broma. 
Ballester et al., Jesús Contreras o els inicis autodidactes de l'antropologia catalana, perifèria 23(1), junio 2018

\section{revistes.uab.cat/periferia}

Era una incògnita. Bé, al final la sorpresa va ser que va haver-hi gent, moltíssima gent. Resulta que havia arribat gent perquè, o bé per la seva pròpia lectura, o perquè a l'institut havien tingut professors d'història que havien fet antropologia i els en hi van parlar una miqueta, doncs sabien que existia una cosa que es deia antropologia. Bé, no sé vosaltres, que esteu a tercer, quina informació vau tenir vosaltres al vostre batxillerat per decidir que volíeu estudiar antropologia?

Paula Villanueva: Jo en el meu cas, m'interessava el tema de la religió i vaig estar investigant, mirant arqueologia fins i tot, i buscant per Internet vaig trobar antropologia, vaig veure el programa de l'Autònoma i em va interessar...

J.C.: Bé, doncs això, va venir gent amb alguna informació, algun estímul o que tenia alguna inquietud pròpia i que va canalitzar-la cap a fer antropologia, però ja us dic, en aquell moment era una incògnita. Escolta, treus 150 places a primer curs (en el primer any em sembla que 120) i quan veus que s'apunten, et preguntes: què saben d'antropologia? I jo tenia por de l'antropologia forense, que la gent vingués pensant que anaven a mirar cranis i que després es podien col-locar a la policia per fer investigacions!

\section{Eli Marcos: Seguint amb el tema, quin creus que ha estat el problema de l'antropologia espanyola, si és que creus que n'hi ha algun...?}

J.C.: Home, això depèn molt del punt de vista, depèn del què es considera com a problema. Suposo que el problema està en termes de reconeixement, de professionalització. El problema del reconeixement ja hi era i fins i tot ara segueix essent-hi. Quan es parla de la sociologia, per exemple, era una disciplina que ja existia, que tenia un cert reconeixement estatal, mentre que I'antropologia no. Una de les coses que a mi m'hagués agradat era tenir més difusió, però clar, cada vegada que trucava una emissora de ràdio per invitar-te a un programa, eren sempre coses d'un esoterisme, de màgia... coses rares!!! Rares en el sentit de que per ells I'antropologia és una disciplina estrictament centrada en "els primitius" o amb coses rares (de la lògica oculta de las societats); o amb el folklore. O sigui, una imatge molt i molt dispersa. De fet, nosaltres contribuïm a aquesta dispersió perquè si 
Ballester et al., Jesús Contreras o els inicis autodidactes de l'antropologia catalana, perifèria 23(1), junio 2018

\section{revistes.uab.cat/periferia}

tornem al Ilistat de títols de comunicacions o de tesis, l'antropologia serveix per a tot.

L'Espanya de les autonomies va contribuir a modificar una miqueta aquesta qüestió, però a partir d'una certa especialització, un cert èmfasi en les qüestions identitàries, nacionalistes, etcètera. I després un dels problemes, segurament també derivat d'això, són les dificultats o la manca de professionalització de la disciplina. Recordo un acudit del Forges, d'un tio que va a I'INEM a buscar feina i el funcionari li diu "¿Profesión?", i la persona li contesta "Antropólogo" i l'altre li diu: "iQue de qué trabaja!" (riures).

Jo diria que aquest ha estat un problema en el qual tenim la culpa la majoria d'antropòlegs i antropòlogues professors. Malgrat que una de les intencions o de declaracions fundacionals de I'ICA era la vinculació amb la societat, la majoria d'antropòlegs professors d'universitat s'han inhibit absolutament de la societat. S'han dedicat a les seves tesis i a les seves coses. També a mesura que les pròpies administracions o institucions han anat coneixent una mica més I'antropologia hi ha hagut demandes de feina per a nosaltres. De fet ara han sorgit laboratoris o grups de consultoria per fer estudis. N'hi ha bastants i alguns que s'han defensat relativament bé. També hi ha empreses que busquen antropòlegs. Aquí no, però a altres països sí. Però, escolta: quants antropòlegs s'escandalitzarien de treballar per una empresa perquè consideren que això és prostituir-se com a disciplina? És que els antropòlegs i les antropòlogues no han de menjar, no han d'exercir? Òbviament allò important és com treballes. Però es clar, tots estàvem en el sancta sanctorum de la universitat. Les discussions que hi havia sobre que l'antropologia aplicada era prostituir-se... Et pots prostituir fent antropologia aplicada, i pots no prostituir-te. I pots prostituir-te sense fer antropologia aplicada. Tant per tant, si t'has de prostituir, que sigui cobrant.

\section{Helena Moreno: Ens ha parlat del seu treball de camp als Andes. Ens podria explicar un poc més com va ser i per què va triar aquest lloc?}

J.C.: Jo no vaig triar Chinchero, vaig anar-hi d'ajudant de I'Esteva. El que sí que vaig triar va ser la temàtica de la meva tesi. A Chinchero aplicava els qüestionaris que 
Ballester et al., Jesús Contreras o els inicis autodidactes de l'antropologia catalana, perifèria 23(1), junio 2018

\section{revistes.uab.cat/periferia}

havia dissenyat el doctor Esteva (jo feia original i còpia en paper carbó, això ara ja no existeix) i fèiem el diari de camp, que també el passava a màquina... La primera vegada que vaig a Chinchero no sabia si hi tornaria més. Però hi vaig tornar I'any següent i encara un altre any. Aleshores és quan vaig decidir continuar anant-hi, no solament per acabar la tesi sinó que vaig continuar fent altres coses que no tenien res a veure amb la tesi. Per què vaig decidir continuar? Hi va haver una certa captació o seducció dels Andes d'una banda. I d'altra banda, un altre dels complexes que jo personalment tenia és que dins de la nostra no-formació en antropologia estava molt clar que el treball de camp s'ha de fer durant 12 mesos perquè has de veure tot el cicle. Però és clar, jo hi anava només 3 mesos. Sumant els mesos que he anat a Chinchero en sumo molts més, fins i tot més de 24 . Ara bé, sempre hi anava a la mateixa època. Jo he estat a Chinchero i mai no he vist Chinchero verd! Perquè sempre hi anava a l'època seca quan ja havien acabat les pluges i ja havien fet la collita. Jo he vist Chinchero verd només en fotos i això encara és una cosa que em persegueix.

En definitiva, jo no vaig decidir anar a Chinchero però sí que vaig decidir les temàtiques. A mi m'interessava l'endevinació i si vaig decidir continuar fou perquè vaig veure que I'endevinació als Andes podia ser un molt bon indicador de les preocupacions de la gent i del canvi social. El recurs als endevins o els pacos havien disminuït considerablement, la qual cosa coincideix amb la instal-lació al districte d'una posta mèdica (que així es deia la infermeria) i la guàrdia civil al Perú (que es diu exactament igual que aquí). Si hi havia hagut un robament, hi havia gent que en comptes d'anar al paco per a què els hi digués qui podia ser, doncs anava a la guàrdia civil a denunciar. En aquest procés de canvi de vegades hi havia gent que anava a denunciar ja al qui es pensaven que havia robat el cap de bestiar a la guàrdia civil. Li preguntaven: "Y tú, ¿cómo lo sabes?", i deien: "Me lo ha dicho el paco." Ah! A la posta mèdica tenien un recurs per intentar obligar a que la gent hi anés en comptes d'anar al paco: si moria algú, per tenir el certificat de defunció que permetés enterrar el difunt havia de constar als fitxers de la posta mèdica. Aleshores l'endevinació, tant pel tipus de consultes que es feien com per la seva davallada, era un indicador dels 
Ballester et al., Jesús Contreras o els inicis autodidactes de l'antropologia catalana, perifèria 23(1), junio 2018

\section{revistes.uab.cat/periferia}

canvis socials que hi havia hagut, tant en un sentit econòmic com institucional. I aquesta va ser la meva temàtica inicialment.

Després vaig descobrir el compadrazgo (jo tinc cinc fillols a les comunitats d'allà) i em va interessar també. El padrinatge és un tema que ha estat molt recurrent a Amèrica Llatina i aleshores jo ho vaig veure com un indicador de les estructures de poder local i supralocal. Vaig buidar tots els llibres de baptisme i de casament que hi havia allà a la parròquia, per veure les xarxes de padrins i els cacics del poble. N'hi havia tres o quatre i n'hi havia un que tenia 200 fillols! Un individu que jo no ho vaig poder constatar però em deien que podia haver batejat vàries vegades els seus fills; i que un padrí dels seus fills va ser el president de la república del Perú. Això és un bon indicador per analitzar les estructures de poder local i supralocal i com funcionen. Bé, en castellà ja es diu "qui no té padrins no es bateja", no?

Llavors em vaig interessar per la arriería, pels traginers, ja en la meva fase més d'antropologia "econòmica-ecològica". Per influència del Murra, perquè els traginers d'alguna manera van d'això dels pisos ecològics. Als Andes la pendent és un fet constrenyent, determinant, estructurant, etc. Els traginers connectaven des dels llocs més alts i apartats de la serra fins als ports del Pacífic, pujant i baixant mercaderies. Jo em vaig interessar per la arriería en un mal moment, perquè vaig anar a fer el meu treball de camp amb els traginers amb la intenció de seguir les seves caravanes en el moment més àlgid de Sendero Luminoso. Quan hi vaig arribar i vaig dir que volia fer això tothom em va dir si estava boig. En definitiva, que vaig estar tres mesos a Ayacucho però pràcticament sense sortir de la ciutat, perquè o et matava l'exèrcit o et matava Sendero Luminoso. Era un moment molt delicat. Aleshores va ser un coitus interruptus, per dir-ho d'alguna manera, el treball sobre els traginers.

I després vaig estudiar les comunitats. La meva darrera recerca al Perú va ser un projecte per intentar analitzar la vigència i les raons de l'organització comunal a la Península Ibèrica i als Andes, perquè hi havia una discussió sobre si les comunitats andines eren una herència de la comunitat espanyola o si eren una evolució de l'ayllu andino. Aquestes quatre línies - I'endevinació com a indicador, el compadrazgo com 
Ballester et al., Jesús Contreras o els inicis autodidactes de l'antropologia catalana, perifèria 23(1), junio 2018

\section{revistes.uab.cat/periferia}

a indicador, la arriería com articulació dels pisos ecològics i la comparació -, han estat el que jo vaig treballar als Andes.

\section{H: Llavors, ha tocat diferents temàtiques dins la disciplina antropològica, no?}

J.C.: Sí! (riu). No diria que totes però moltes. Mira, per exemple, a nivell docent I'Antropologia econòmica que pràcticament me la vaig inventar a partir dels no res; I'Etnologia de la Península Ibèrica; vaig donar a la facultat i també a l'Autònoma un curs d'Antropologia de la comunicació, a la Facultat de Ciències de la Comunicació: vam compartir amb en Joan Prat una Antropologia de la comunicació i una Antropologia de la publicitat. Després Etnologia andina, Antropologia del camperolat i Antropologia de l'alimentació, que és una de les que perdura fins el darrer moment. També em vaig inventar una assignatura que ha tingut força continuïtat: Antropologia i problemes de la societat contemporània. Jo sempre he defensat el valor heurístic d'estudiar els "primitius" per la lògica oculta de les altres societats, però sempre he considerat que la sociologia eren una miqueta els nostres grans competidors i que se'ns ho menjaven tot. Amb el temps resulta que no solament se'ns ha menjat terreny la sociologia, que aquests van arribar primer, sinó que fins i tot hem patit l'intrusisme (sense cap mena de reacció per part dels antropòlegs) de coses tan estranyes com la pedagogia, que ha tingut més mercat amb el tema del multiculturalisme que l'antropologia mateixa. La qual cosa és un element de reflexió per la comunitat dels antropòlegs, dins de la qual m'incloc. L'antropologia ha d'ajudar a repensar la societat contemporània. Sempre he dit també que en I'antropologia les comparacions no només no són odioses sinó que són heurísticament necessàries. La societat contemporània planteja una gran quantitat de problemes per a una antropologia del parentiu, per a una antropologia de la religió, per a una antropologia econòmica. Per exemple, totes les monedes alternatives, això es antropologia clàssica fins a cert punt.

He tocat moltes temes, alguns amb una mica més de fortuna i continuïtat que d'altres. Això de l'antropologia de I'alimentació - perquè ara jo passo per un especialista en aquest tema -, va ser el fruit també d'una miqueta d'interès. Vaig 
Ballester et al., Jesús Contreras o els inicis autodidactes de l'antropologia catalana, perifèria 23(1), junio 2018

\section{revistes.uab.cat/periferia}

llegir un article, "Gastronomía y gastro-anomía", que em va agradar moltíssim. Era d'una transversalitat extraordinària entre biologia i cultura, i jo en aquells moments estava donant antropologia econòmica. Teòricament allò econòmic és producció, distribució i consum, però el consum pràcticament no es tocava. A mi m'interessava la part del consum i em vaig interessar per l'alimentació i pel vestit. Em vaig començar a preparar unes quantes classes a partir d'aquest article (és d'un sociòleg francès que ara es defineix sòcio-antropòleg, en Claude Fischler) i em va semblar interesantíssim. Dedicava tres o quatre classes a explicar aquesta temàtica. Com que em va interessar, vaig demanar un ajut al Ministeri d'Agricultura per preparar un llibre que era una selecció d'articles de la temàtica d'antropologia de l'alimentació. Em van donar l'ajut, vaig preparar el llibre i també, simultàniament, vaig oferir a al Museu de la Ciència un cicle que es va titular "Antropologia de I'alimentació", que va tenir un gran èxit i que a més a més va tenir una repercussió tremenda. Em van trucar moltes emissores de la ràdio, el curs es va haver d'ampliar i es va afegir una sala més gran. Aleshores em van començar a invitar gent de nutrició, tot i que no en tenia gaire idea. Total que jo, que ja anava variant una mica cada any el programa d'Antropologia econòmica, degut al gran èxit vaig fer una assignatura, Antropologia de la alimentació, que era una optativa. Doncs escolta, van començar a haver-hi demandes des del camp de la nutrició, ciències de la salut, de la indústria. Tot això em va fer mantenir-me en aquesta especialització, de tal manera que a partir de aquí agafo també projectes europeus. El meu primer projecte europeu tenia que veure amb I'alimentació, com tots el altres europeus que he realitzat. Jo no imaginava que fos la primera persona dins de les ciències socials a Espanya a tocar el tema de l'alimentació com a tal. Ara hi ha moltíssimes tesis sobre antropologia de I'alimentació. 
Ballester et al., Jesús Contreras o els inicis autodidactes de l'antropologia catalana, perifèria 23(1), junio 2018

\section{revistes.uab.cat/periferia}

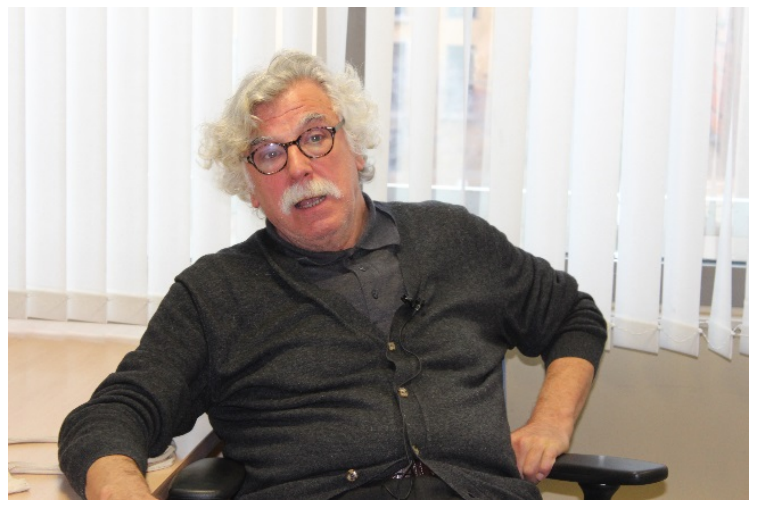

En definitiva, vaig tenir aquest èxit inesperat i ara m'he convertit en un especialista en antropologia de I'alimentació, que alguns es pensen que sóc nutricionista i tot, imagina't! He tocat moltes coses amb més o menys fortuna, algunes més ocasionals... Jo, ara que es parla tant de que s'han de fer articles en revistes indexades i tot plegat, tinc més de 200 articles publicats i no he enviat mai un article per ser publicat. Mai! Fins i tot els darrers articles que tinc en revistes d'impacte són sol-licitats. Jo tinc un greu defecte i es que no sé que dir que no: em demanaven una cosa i jo m'esforçava i la feia. Aleshores tenia coses d'allò més inversemblants, que he tocat perquè no he sabut dir que no. Però això ho dic com a defecte, eh! No he estat gens selectiu.

\section{H.: I actualment és director de l'Observatori de l'alimentació?}

J.C.: No, ja no. Fa dos anys que ho vaig deixar perquè s'havia de preparar el relleu i no volia que coincidís amb la meva jubilació. Hi ha hagut una transició. Continuo sent investigador de I'Observatori de I'alimentació, però ara hi ha una co-direcció entre la Cristina Larrea, que és professora d'aquí el departament, i el Joan Ribas.

\section{H.: I com hi va arribar?}

J.C.: Doncs mira, igual que en el seu moment I'ICA era una necessitat, hi va haver un moment en que hi havia gent que volia treballar en el tema de l'alimentació i no hi havia res. Si tenies un projecte europeu podien sortir un, dos o tres contractes, però s'acabaven quan s'acabava el projecte. Ara l'alimentació està de moda, per moltes raons, i vam crear l'observatori perquè també estan de moda. Però en definitiva la intenció era contribuir. També hi havia el tema dels grups de recerca. 
Ballester et al., Jesús Contreras o els inicis autodidactes de l'antropologia catalana, perifèria 23(1), junio 2018

\section{revistes.uab.cat/periferia}

Aquest és un altre dels condicionaments que hi ha a la universitat espanyola. Ara es privilegia el grup, malgrat que jo sempre he dit que les ciències humanes i socials el nostre laboratori és el carrer; o la selva, és igual. Aleshores aquell condicionament ja existia: si tenies un grup de recerca reconegut tenies finançament. I d'altra banda, la nostra intenció també era projectar-nos una miqueta perquè poguéssim tenir demandes de treballs i d'estudis. Així es crea l'observatori. En un principi es deia Grup d'Estudis Alimentaris. Després hi va haver un primer canvi i li vam dir Observatori Permanent dels Comportaments Alimentaris (OPCA), però era massa complicat i vam fer I'Observatori De L'Alimentació (ODELA). La intenció era no solament intentar accedir al ajusts específics pels grups de recerca consolidats sinó donar-li projecció per tenir més estudis a demanda. Dins de I'observatori ens interessa tot, hem fet estudis que nosaltres mateixos hem pensat però també hem fet projectes que ens han encarregat. Hem fet antropologia aplicada perquè també has de treballar, has de donar feina. I per altra banda per convenciment: si el que nosaltres fem només ho han de llegir els i les antropòlogues, malament.

\section{H.: El 22 de gener passat va venir al CCCB Vandana Shiva, que és una ecologista de l'Índia que ha tractat temes de l'aigua i de l'accés a aquesta. Considera que I'aigua és un element a valorar a l'hora d'analitzar les pràctiques alimentàries?}

J.C.: No és que sigui una part, és que és fonamental. Quan parlem de pràctica alimentària, parlem de pràctiques (comportaments alimentaris) i també de la cadena alimentària com a tal (el procés de producció). L'aigua té un punt doble de valor: la necessitat de l'accés a l'aigua per a la major part de producció d'aliments animals o vegetals (pel reg, per als animals) i després l'aigua pel consum humà. Aquest és un dels principals problemes que hi ha. És un problema com a recurs escàs o com a recurs apropiat, però és un problema també per la facilitat de contaminació que té. Mira, jo vaig fer una conferència sobre I'aigua pel govern andorrà quan era I'any de I'aigua. I vaig recollir una gran quantitat de refranys que tenen a veure amb l'aigua. N'hi ha un que diu "Aigua corrent no mata a la gent". De fet, el consum de vi ha estat altíssim a Catalunya. Hi ha un metge a finals del segle XIX que afirma que a la Vall d'Aran a l'estiu es consumien 3 litres de vi per persona i any. Jo no sé l'exactitud del 
Ballester et al., Jesús Contreras o els inicis autodidactes de l'antropologia catalana, perifèria 23(1), junio 2018

\section{revistes.uab.cat/periferia}

registre del metge aquest, però jo parlant amb els pagesos em deien que no es consumia aigua perquè era perillosa, i no és una frase de borratxo.

Per exemple, a Barcelona la higienització completa de l'aigua és del anys 50. La higienització de I'aigua es comença a practicar a finals del XIX, o sigui, com qui diu fa dos dies. I I'aigua no higienitzada o contaminada és una de les fonts de malaltia més importants que hi ha a moltes regions del món. Per tant, l'aigua és un recurs fonamental per a la producció $\mathrm{i}$ indispensable per als humans. Jo consumeixo 3 litres d'aigua però en forma directa d'aigua només mig litre als matins en dejú. Ja ho diuen: "Agua en ayunas, o mucha o ninguna". Un altre refrany! Jo sóc molt de refranys, avui no us n'he dit gaires, ja és rar. Ara està de moda I'aigua: s'han de beure dos litres diaris d'aigua, tot i que no necessàriament s'ha de prendre una ampolla de dos litres diària, perquè si prens un cafè o un te també prens aigua. Nosaltres som el 70 o $80 \%$ aigua, qui ho diria, eh!

Però insisteixo, és un recurs que continua provocant quantitat de conflictes. Per exemple, a Amèrica llatina, ara ja no ho treballo tant però vaig dirigir una tesi sobre els conflictes de l'aigua al nord de Xile. Les empreses mineres de tota la zona andina necessiten aigua per a les seves explotacions i és una aigua que foten o intenten fotre a les comunitats indígenes pageses. És un recurs escàs i fonamental per la producció, que ha estat intentat apropiat, que té molta legislació. Per exemple, aquí a València encara és molt famós el Tribunal d'Aigües. També es fonamental per la producció dels aliments: els plats universals que hi ha (el cocido, l'escudella, el sukiyaki, el bollito italià) són bullits. És un recurs fonamental per cuinar una gran varietat de plats i pel consum directe.

\section{H.: Llavors, la forma com ens alimentem també diu molt de nosaltres, no?}

J.C.: Això diuen: "Somos lo que comemos", "Dime que comes y te diré quien eres". Són algunes de les dites que hi ha al respecte. Nosaltres un dels estudis que vam fer amb la meva col-lega Mabel Gracia el vam titular Comemos como vivimos. Sí, diu molt de nosaltres. Què passa amb l'alimentació? Doncs que és una cosa que fa tothom. Mengem vàries vegades al dia, de diferents maneres. L'alimentació ens organitza la vida, ens organitza el temps: el temps de dinar, el temps de sopar, el 
Ballester et al., Jesús Contreras o els inicis autodidactes de l'antropologia catalana, perifèria 23(1), junio 2018

\section{revistes.uab.cat/periferia}

temps de berenar, "el coffee-break"... Té moltes dimensions. Jo sempre dic que en el cas de l'alimentació l'aportació de l'antropologia és que no solament ens interessem per què menja la gent sinó també què no menja, que realment és tan important una cosa com l'altra. Això es important, què menja? Quan menja? On menja? Amb qui menja? Com menja? Per què menja el que menja? Per què menja com menja? Per què menja el què menja segons amb qui menja? etc. Respondre totes aquestes preguntes té a veure amb l'organització del temps, amb l'organització domèstica, eventualment amb la teva salut o malaltia, amb la teva percepció o creença... Escolta, tu pots ser jueva i has de seguir una alimentació determinada. O pot ser que siguis catòlica i avui, teòricament, com que és divendres no hauries de menjar carn. Ara hi ha gent que fa bacallà els divendres però que ho fa per habitus que diria Bourdieu. En definitiva, l'alimentació reflecteix molts aspectes de la cultura i dels nostres comportaments. I si no menges també.

\section{H.: I com s'alimenta vostè?}

J.C.: Jo? Jo m'alimento a gust (riu) Hi ha una dita que diu "El mejor cocinero es el hambre". Jo tinc la sort de que tinc gana. Mira, hem tingut dos projectes europeus i dos projectes per I'IMSERSO sobre alimentació i gent gran. En una de les recerques una senyora gran li deia a una altra: "Ai, quina sort tens que no has perdut la gana!". Tenir gana et permet gaudir de quan menges i et permet també moltes coses. Doncs jo tinc la sort de tenir gana, per tant menjo a gust. No tinc tabús però sí que tinc alguns rebutjos: no puc amb el fetge, el cor i el ronyons. Això no és perquè a casa meva no es mengés, perquè per la meva mare a l'època, per raons econòmiques i per raons de creences de salut, fer fetge era un aliment fonamental, sobre tot pels nens. I que a més a més era baratíssim. Tenia els dos avantatges, perquè rarament passa que allò que és bo sigui barat. A casa meva tothom en menjava però jo no he pogut mai amb el fetge.

Us explicaré una anècdota. Jo era molt religiós, molt catòlic, i cada any quan arribava fi de curs jo feia una promesa. A segon de batxillerat no vaig estudiar gaire i vaig fer una promesa: "Señor, os prometo que si apruebo comeré dos filetes de hígado" (ho dic en castellà perquè jo sóc andalús, eh!). Vaig aprovar i vaig dir-li a ma mare que 
Ballester et al., Jesús Contreras o els inicis autodidactes de l'antropologia catalana, perifèria 23(1), junio 2018

\section{revistes.uab.cat/periferia}

havia fet aquella promesa, perquè ella ja no em feia fetge llavors, als 12 anys. A les dues de la tarda començo a menjar fetge..., a les quatre acabo amb el primer filet. La meva mare ja estava que no podia més i em va dir: "Déjalo, que Dios ya te perdonarà!" (riures). I no em vaig acabar el segon filet. A l'any següent vaig prometre que si aprovava aniria descalç a una ermita que hi ha prop de Puigcerdà, que hi ha 4 km, i cap problema. Però no vaig poder amb el fetge. Va ser la darrera vegada que vaig menjar fetge.

L'altra limitació la tinc amb la llet. Jo sóc un mamífer normal i els mamífers normals perdem la lactasa, I'enzim que permet digerir la lactosa després de l'alletament. Jo sóc normal i he perdut la lactasa, no digereixo la lactosa. No sóc un malalt que no tolera la llet, sóc un mamífer normal. En fi, la llet i el fetge no son tabús familiars ni culturals, però no puc amb ells. Apart d'això, puc menjar qualsevol cosa i a gust. De moment tinc gana i tant de bo no la perdi. Perquè tal i com estan les coses és una de les poques satisfaccions que determinades persones podem tenir fins i tot quan som grandets ja, que és el meu cas.

\section{H.: El slow food és un corrent que pretén trobar el sentit a l'alimentació i té com a base una dieta basada en abundants nutrients alimentaris. Creu que ha estat per això que a partir d'aquest moviment varen sorgir els identificadors alimentaris?}

J.C: No. A veure, si per identificadors alimentaris entens les certificacions diverses que hi ha, com per exemple denominacions d'origen protegides, indicacions geogràfiques protegides, producte de qualitat, producte tradicional, etc..., moltes d'elles són molt anteriors al slow food. Ara slow food ha creat les seves pròpies però la majoria d'elles són anteriors. La primera d'elles va ser la denominació d'origen que va ser creada a França a principis del XX per protegir els productors de vins francesos d'alguns "imitadors" o algunes pràctiques d'elaboració de vi que es consideraven fraudulentes i que anaven en detriment dels productors. França ha estat un país que sempre, governés més la dreta o no tan la dreta, ha protegit molt la seva pagesia. Ara la denominació d'origen és un element més de mercat. Ja no és només protegir els productors que elaboren un producte (el producte pot ser des d'un calçot, que no 
Ballester et al., Jesús Contreras o els inicis autodidactes de l'antropologia catalana, perifèria 23(1), junio 2018

\section{revistes.uab.cat/periferia}

hi ha una transformació sinó que és una tècnica de conreu, o un vi, que sí que té un procés llarg i que intervenen molts factors), protegir el productor que té un determinat saber, o que ho fa en unes condicions ecològiques ben caracteritzades, sinó que ara també és un element de màrqueting. Si tu aconsegueixes una denominació per un producte - sigui un formatge, un vi o un pa -, és un element de valor afegit.

Ara que es parla molt d'innovació en tots els terrenys (innovar o morir!) en I'alimentació es fa molt això d'innovar. Una innovació fantàstica és el pa integral. El pa integral és un pa que és més car avui que el pa blanc. Però fa 30-40 anys el pa integral es deia pa moreno i era més barat que el pa blanc. Li canvies el nom i el vens més car. Ara estic caricaturitzant però han passat moltes coses perquè en comptes de moreno se li digui integral i perquè la gent estigui disposada a pagar més per un pa que abans era més barato que el pa blanc. Quines coses han passat? Una és que el consum de fibra ha disminuït $i$ això ara és un problema perquè mengem poca fibra. Hi ha molta gent que es pren segó (les closques del blat), que això abans es donava a les gallines i porcs i ara hi ha gent que ho barreja al iogurt, per exemple. Tenim dèficit de fibra $\mathrm{i}$ ara tots els productes es venen perquè són enriquits amb fibra. Fins i tot va sortir un xoriço "enriquecido con bifidus activo, para mejorar tu flora intestinal". Tenim problemes amb el tema intestinal... (riures)

Aleshores han proliferat els tipus de certificacions. Jo els hi dic als meus estudiants: us hauríeu d'inventar una certificació que això dóna beneficis! Perquè són valor afegit: en un moment en que hi ha una superabundància alimentaria tremenda, per una banda; i que les pors en relació a l'alimentació són també tremendes, doncs busques elements que et donin seguretat o confiança. En relació a una determinada qualitat, a unes determinades característiques, a un determinat procés d'elaboració o que poden fer un bé o altre en termes de salut. Aleshores és en aquest context que proliferen les certificacions.

La iniciativa del slow food i les seves declaracions de principis em semblen molt bé. I valoritzar determinats productes i els seus productors, em sembla molt bé. Però hi ha una vessant de màrqueting important, amb uns preus tremendos que només 
Ballester et al., Jesús Contreras o els inicis autodidactes de l'antropologia catalana, perifèria 23(1), junio 2018

\section{revistes.uab.cat/periferia}

poden comprar els rics. Aleshores a la teva pregunta, les denominacions són molt anteriors al naixement del slow food. Si que slow food ha creat les seves pròpies i aquesta proliferació de denominacions o certificats d'una banda, i declaracions i interessos de l'altra, respon a diferents criteris al Ilarg de la història. En un principi les raons de la creació van ser molt precises i ara són molt diverses.

De tota manera en moltes ocasions hi ha gent que no es vol acollir a la denominació, perquè la denominació o qualsevol tipus de certificació necessita complir una sèrie de requisits i moltes vegades hi ha productors que no els interessa complir segons quins requisits; eventualment la diferència de preu que poguessin tenir no els compensa. Aquí a Catalunya, tenim un cas bastant paradigmàtic, per no dir contradictori, en relació a les denominacions d'origen. Aquí tenim $\begin{array}{llll}11 & 0 & 12\end{array}$ denominacions d'origen de vi: Bages, Penedès, Priorat, Terra Alta, Alella, ... etc. I tenim una denominació d'origen que és Catalunya. Ostres! Si resulta que Penedès teòricament és una "tradició", un paisatge determinat, blablabla..., i després resulta que hi ha una denominació que inclou els 11 paisatges i les 11 particularitats? No té sentit! Hi ha gent que s'acull a les denominacions per raons econòmiques, són estratègies de defensa. Estem en un moment de proliferació de denominacions amb diferents lògiques, però això dóna lloc a la "dictadura del certificador". Ja us dic, creeu una certificació i potser estareu creant-vos un lloc de treball.

\section{H.: Bé, ara t'has jubilat de la Universitat de Barcelona però això no vol dir que deixaràs de fer antropologia, no?}

J.C: Jo antropologia $n$ 'he fet sempre. Fins i tot la meva segona exdona (tinc dues exdones), de vegades s'enfadava amb mi i em deia: "iConmigo no hagas de antropólogo!" (riures). Jo sempre dic que per saber si una persona és antropòleg o antropòloga s'ha de comptar quantes vegades diu "depèn". Així com jo tenia un dèficit de formació en els inicis quan era antropòleg, doncs ara potser tinc un superàvit de formació. Jo diria que és com una actitud vital, intentar comprendre les coses.

Un proverbi xinés diu que "tenim dues orelles i una boca": hem d'escoltar dues vegades i parlar nomes una. Jo això procuro aplicar-ho; a vegades em costa però 
Ballester et al., Jesús Contreras o els inicis autodidactes de l'antropologia catalana, perifèria 23(1), junio 2018

\section{revistes.uab.cat/periferia}

procuro aplicar-ho. Trobo que això és molt antropològic. Els antropòlegs han de mirar, observar, escoltar, comparar,... Això es una actitud. En un altre nivell, en el nivell d'activitats, escolta: "arriero soy, a donde me llaman voy". Ara per exemple, estic preparant una conferència, ara m'han demanat un llibre d'història d'antropologia de I'alimentació... És una manera d'entretenir-me.

\section{H.: Llavors, ara en què està treballant? 0 en què li agradaria treballar en el futur?}

J.C.: Ja et dic, m'han demanat un llibre d'història i antropologia de l'alimentació que $\mathrm{m}$ 'ha anat molt bé perquè em servirà per intentar donar un fil coherent a moltes de les coses que he publicat, que estan una mica disperses, i convertir-ho en un llibre. Això em tindrà entretingut un temps. Em demanen forces conferències aquest any; de moment en tinc com 9 o 10, de temàtiques relativament diverses. A més a més, com que una classe o una conferència fins que és una hora abans no l'has acabat de preparar, doncs vaig fent. En un altre nivell, m'han fet un encàrrec sobre el consum de la carn de conill. El sector de la carn d'aquest país (i d'altres països) estan molt preocupats perquè la carn és un perill. Una carn poc perillosa -en el sentit dels càncers -, és la carn de conill. Però el sector del conill està molt preocupat perquè disminueix el consum de conill i m'han demanat un estudi. És un repte que m'entretindrà amb el conill. I d'altra banda, tinc també un projecte a nivell europeu que s'està preparant ara (encara no s'ha presentat i caldrà veure si s'aprova o no) sobre l'evolució que ha tingut dins dels països del mediterrani el consum de llegums, cereals i oli, en relació a això que en diuen "la dieta mediterrània". Si aquest projecte s'aprova doncs "en ello estaremos". I hem d'organitzar un congrés pel juny de 2019 el títol del qual serà "Patrimonis alimentaris, sostenibilitats i turismes". Tot en plural, que això és una altra de les meves vessants antropològiques. Vaig llegir fa molt temps, no me'n recordo qui ho deia que "I'antropologia va començar quan a la paraula cultura se li va afegir una essa: ja no es parla de cultura sinó de cultures". Doncs jo penso que s'ha de parlar de patrimonis alimentaris en plural, perquè hi ha molts tipus de patrimonis i patrimonialització. De sostenibilitat també hi ha molts tipus o graus, i turisme també hi han molts tipus, però intentaré mirar això pel juny del 2019. 
Ballester et al., Jesús Contreras o els inicis autodidactes de l'antropologia catalana, perifèria 23(1), junio 2018

\section{revistes.uab.cat/periferia}

\section{H: Per acabar l'entrevista ens podria contar alguna anècdota?}

J.C: A veure... Segurament n'hi han moltes, però n'hi ha una que he explicat moltes vegades, que és "molt antropològica" i té a veure amb això de la 'essa' i de l'alteritat. Perquè l'antropologia és una disciplina de l'alteritat: s'estudien els altres. Doncs jo vaig donar Tècniques d'investigació (una altra de les assignatures que em vaig inventar) i anava amb un grup d'alumnes i els repartia per diferents pobles de les Garrigues. Un any vam arribar a la Pobla de Granadella i vam anar a dinar abans de que la gent es repartís. Estàvem 10-12 alumnes (quasi tot noies, només havia un noi que jo recordi) i a la taula del costat hi havia dos homes que miraven a les noies. Jo vaig veure que tenien ganes de xerrar i vaig dir: "Començarem a fer treball de camp i observació". Eren tractants de bestiar i explicaven que justament havien estat comprant ovelles i animals. I jo per tal de donar-los conversa els vaig preguntar com ho feien. Em van dir: 'Nosaltres tocant les dents sabem si han tingut alguna malaltia, quina edat tenen, etc.' I com que això de l'etno-classificació és una cosa molt antropològica, no?, els hi vaig preguntar: "Escolti, que em podria explicar amb una mica més de detall això de les dents?". I el tio em mira i em diu: "Miri, no li explico perquè vostè no ho entendria". Osti, I'alteritat, tu! La antropologia at home era això. Som dues cultures completament diferents: la teva "barcelonina" i la meva que sóc un tractant de bestiar. A veure, suposo que $\mathrm{m}$ 'ho va dir perquè I'home tenia mandra d'explicar-m'ho, no? Però em diu "no li explico perquè vostè no ho entendria". Què vull dir amb això? Doncs que l'alteritat està al nostre costat. Hi ha un famós antropòleg francès, en George Condominas, que té un llibre molt maco que es diu Lo exòtico és lo cotidiano. Doncs ja veus l'alteritat: un home no m'explica una cosa perquè ja dóna per suposat que jo no l'entendré. Imagina't si hem de ser de cultures o de mentalitats diferents. Bé, és una anècdota. En puc explicar més, però m’heu dit una i és una.

\section{H: Doncs ja està. Moltes gràcies.}

J.C: D’acord. Molt bé, moltes gràcies a vosaltres. 
Ballester et al., Jesús Contreras o els inicis autodidactes de l'antropologia catalana, perifèria 23(1), junio 2018

revistes.uab.cat/periferia

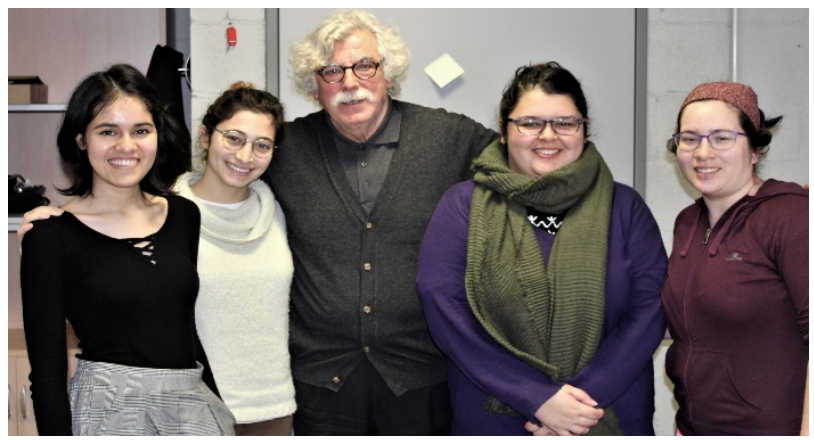

Andrea Milán, Paula Villanueva, Jesús Contreras, Helena Moreno i Jessica Morente 